\title{
Consumer Understanding of Nutritional Supplements: An Irish Context
}

\author{
Julie Ann Walsh \\ Department of Organisation \& Professional Development, School of Business \\ CIT, Bishopstown, Cork. Ireland \\ Dr Angela Wright (Corresponding author) \\ Department of Organisation \& Professional Development, School of Business \\ CIT, Bishopstown, Cork. Ireland \\ E-mail: angela.wright@cit.ie
}

Received: December 8, 2015

Accepted: December 27, 2015

doi:10.5296/ber.v6i1.8912

URL: http://dx.doi.org/10.5296/ber.v6i1.8912

\begin{abstract}
Nutritional Supplements have been available in Ireland for over thirty years. Originally available in health food stores only, supplements now have several distribution channels including pharmacy, practitioner, and online. Recommendations for consumption can come from many sources including general physicians, alternative practitioners, dieticians and nutritionists. The demand for Nutritional Supplements has increased over the years, and the industry has expanded exponentially. Nutritional Supplements provide an important opportunity to optimize illness prevention. As scientists and health professionals start to understand the value of Nutritional Supplements in terms of the prevention and treatment of disease, consumers follow suit. Market growth of Nutritional Supplements is reliant both on market positioning and the distribution strategies and channels chosen by the industry. The success or failure is dependent on how effectively and efficiently their products are sold through marketing channel members (e.g., agents, wholesalers, distributors, and retailers).

An examination of the distribution channel most appropriate to the purchase of Nutritional Supplements, and advice on their consumption has never been investigated in Ireland to date; hence, this research will be applicable to those involved in this specific industry.

A mixed method research approach was undertaken in this study to enable a thorough overview of the industry as it currently stands in Ireland. This research examines the quality
\end{abstract}


of education of those who are distributing, retailing and/or recommending Nutritional Supplements. Qualitative data was collected through semi-structured interviews with twelve participants working within the Nutritional Supplement sector. This research also examines the thoughts of the consumer, relative to preferred distribution channels and who they deem most appropriate as advisors of Nutritional Supplements in Ireland. This was executed through a quantitative process and the consumer data was collated via an online survey.

A key finding of this study is that those who are considered best qualified for consultation (general practitioner, dietician and pharmacist), are actually not qualified enough to distribute Nutritional Supplement advice. Health food stores are the preferred distribution channel by consumers; however, Health store workers are not recognised as the most trustworthy for advice. This research will benefit those involved in the manufacture and distribution of Nutritional Supplements in Ireland.

Keywords: Nutritional Supplements, Health stores, Consumer Behaviour

\section{Introduction}

This current research study is an academic examination of the Nutritional Supplement Industry in Ireland, with the core purpose of determining the best and most appropriate distribution channel for Nutritional Supplements. Additionally, this current study will determine the level of Nutritional Supplement training available presently in the industry. This study researched the industry both from a consumer perspective and from the side of the retailer and distributor, allowing a broader view of the industry as a whole. The subject matter of this investigation is topical; in 2013/2014, as legislation is changing on the labelling and the availability of Nutritional Supplements. As more retailers enter the commercial space of Nutritional Supplements, it is important to investigate how well those currently retailing them are trained. To date, no literature is available specific to the Irish Nutritional Supplement Industry, and thus this research aims to demonstrate a significant contribution to knowledge with this overview of the industry.

\section{Literature Review}

Nutritional Supplements are a broad category of nutrients and other bioactive substance that contribute significantly to total dietary intakes (Dwyer, 2005). Nutritional Supplements contain one or more dietary ingredients (e.g., vitamins, minerals, amino acids, herbs or other botanicals) and are intended to supplement the diet (U.S. Food and Drug Administration, 1994). The European Food Safety Authority (EFSA) defines Nutritional Supplements as:

Concentrated sources of nutrients or other substances with a nutritional or physiological effect, whose purpose is to supplement the normal diet, (efsa.europa.eu).

Nutritional Supplements are widely used across all ages and user groups and constitute a considerable business sector in most developed countries (Petroczi et al., 2010). Supplements (sold as dietary, food or Nutritional Supplements) are freely available to consumers who, by and large, rely on information freely available regarding safe use as printed on the label (Petroczi et al., 2010). Distributors of Nutritional Supplements, among other market actors, 
are contributing at different levels and with different strategies to consumers' level of knowledge of, and preferences for Nutritional Supplements. Their behaviour also plays a role in the trust/mistrust in Nutritional Supplements (Hamzaoui-Essoussi et al., 2013). There are several distribution channels of Nutritional Supplements available to the consumer in Ireland: online, pharmacy, Dietician, General Physician (G.P.), health food stores and Complementary and Alternative Medicine Practitioners (CAM Providers). The question about who to trust for advice is crucial in many volatile businesses, as is the ability to be trusted (Blomqvist, 1997). Because people want high quality information, they often follow advice from advisors with high levels of expertise and confidence, and a reputation for accuracy (Jodlbauer \& Jonas, 2011). When advice costs money, people weigh their personal opinions less than others. When advice is free, people weigh their personal opinions more than others (Gino, 2008). Practitioners often call trust the most important success factor for their business (Blomqvist, 1997). Although medical professionals constitute the best source of one-to-one health information and assessment, the cost and time required to visit health providers prevent many people from seeking their advice in non-urgent as well as critical conditions (Song \& Zahedi, 2006). The success of medical advice depends most importantly on the fact that patients trust that their physicians are competent, take appropriate responsibility and control, and give their patients' welfare the highest priority (Mechanic and Schlesinger, 1996). Social trust in medicine and General Physicians reflects public attitudes and is shaped by the power attributed to their education, media and current events (Mechanic and Schlesinger, 1996).

Power has been defined as the capacity or ability to direct or influence the behavior of others or the course of events (Oxford Dictionary, 2013). As power increases, the tendency to take advice decreases, thereby exacerbating the natural inclination people have to discount advice from others, even when that advice could help them to perform better or make better decisions (See et al., 2011). Information given by health professionals such as General Practitioners has more of an effect on women's dietary change, for example, than information obtained by other sources (de Jong-van der Bert et al., 2004; Verbeke and de Bourdeaudhuij, 2007). Patients are known to use the internet for their own research for medical and nutritional queries (PewResearch Centre, 2000). Sillence et al., (2006) note that the expanding volume of websites coupled with fears over the quality of information has led to questions being raised about how people make 'trust' decisions with regard to online health sites. Less than half of the medical information available online has been reviewed by doctors (PewResearch Centre, 2000) and few websites provide sufficient information to support patient decision-making with many also heavily jargon-laden and difficult to read (Smart \& Burling, 2001). It has been reported that $80 \%$ of adult Internet users have gone online for general health information (Fox \& Fallows, 2003). Rozmotvits \& Ziebland (2004) showed that people search online for health information and advice for a number of reasons. Some want to be better informed, better prepared when meeting the doctor, or are searching for support, alternative answers or reassurance (Rozmovits \& Ziebland, 2004). In terms of the retail of Nutritional Supplements, the individual selling the product may influence the purchase decision, whether it is the type of product purchased, quantity of products purchased or brand(s) purchased. The trust of personal sales is believed to depend upon trust, i.e., on the customer's willingness to trust the salesperson and the salesperson's ability to demonstrate 
trustworthiness (Blomqvist, 1997).

Kennedy, (2005) demonstrated that Nutritional Supplement consumption was associated with positive assessments of health status and behaviours such as regular exercise and smoking cessation. Most users appeared to self-prescribe herbs and natural products; only a small proportion saw a Complementary or Alternative Medicine (CAM) provider (Kennedy, 2005). The increasing use of Nutritional Supplements in general is one example supporting the notion of an aspiration towards better health through preventative measures (Greger, 2001). According to the World Health Organization, complementary and alternative medicine (including the use of Nutritional Supplements) is a growing health system with economic importance worldwide (Frenkel et al., 2008).

\section{Methodology}

As there are several different distribution channels for Nutritional Supplements in Ireland, it was important to investigate the level of expertise each channel possesses. Also worthy of investigation was the level of trust the general consumer has toward each channel. It was then easy to decipher the best distribution channel for Nutritional Supplements. This research adopts an exploratory approach to develop an understanding of the distribution channels of Nutritional Supplements in Ireland. Relevant literature was reviewed to determine the gaps in the literature, and to shape the direction of the research in relation the Irish market. Several literary sources were consulted to establish the key findings within the extent of the literature on Nutritional Supplements including published papers, recent and unpublished sources such as unpublished papers, relevant books and websites. For the empirical data, a mixed methods approach was applied - both quantitative \& qualitative methods.

The qualitative approach was used to gather information-rich data from those working in the Nutritional Supplement Industry via interviews. In total, twelve interviews were conducted for this current study; nine face-to-face \& three by telephone. Semi-structured interviews were employed for the qualitative part of this study which involved a sustained encounter between the researcher and a single participant taking between 20 minutes and 1 hour. All interviews, whether face-to-face or over the phone were recorded and subsequently transcribed.

The quantitative element used an online survey to access consumers of Nutritional Supplements, and to determine the trust preferences of consumers in relation to the acceptance of advice. A web-based survey was published online using the commercial provider, Survey Monkey. This method allowed the researcher to analyse a larger portion of the population in an inexpensive and timely manner. An online, self-administered survey, containing a combination of Likert scale and open-ended questions was employed to investigate the methods consumers employ to gain knowledge on Nutritional Supplements, and subsequently, where they purchase same. A total population of 150 consumers completed the survey. 


\section{Main Findings \& Discussion}

\subsection{Levels of Expertise}

The findings of this study reveal an interesting fact that practitioners, from varying fields contributing to this research, all consider themselves experts in the field of Nutritional Supplements and are confident to give advice on the use of same to customers:

I definitely think the professional clinical nutritionists and dietetics are ideally placed to make the recommendation. I would say that you know while doctors and nurses can sometimes do that, they're often not in an ideal position in terms of training or being up-to-date in the field of nutritional science,

Representative from the Irish Nutrition and Dietetics Institute (INDI).

A Dietician made a similar claim:

I think Dieticians are very well qualified to actually advise people on the different types of supplements.

The Pharmacist contributed to the study stated that:

At least with your Pharmacist as your first point, you know the patient's prescription, so, if there are any nutritional adverse effects or benefit, then that can be looked at together.

A Health Food Store owner believes that this particular outlet was the best distribution channel for supplements:

I think a health shop is an excellent place and you know that you can trust the brands there. You can certainly trust those people. Online, you never know what you are getting, and as for Pharmacies, I just don't think that their training is as thorough.

Each participant was questioned on the level of training they had in relation to Nutritional Supplements. The question was also posed as to whether any training specific to the industry had been taken within the last year. There was significant variation across the sector, with many people in the industry receiving no formal training whatsoever. Most notable were the buyers for the Pharmacy sector:

The manufacturers tend to be training you as they are selling their product to you,

Pharmacy Wholesaler.

One pharmacy wholesaler commented that:

From time to time, you sit in on some supplier training and some of the suppliers are very knowledgeable, and give you good detail of the product, but I haven't done any formal training.

For clinical Dieticians, on-going training (Continual Progressive Development) is currently on a voluntary basis. The following Dietician outlines that:

I haven't had any experience of training in my area of Early Intervention Dietetics. 
In terms of the training received by doctors, a Nutritionist made reference to their training:

Most doctors are receiving a number of hours, not days, but hours on nutrition. So, if I wanted to know which drug was most appropriate for my treatment, I would go to a doctor. I wouldn't go to a nutritionist. If I want to know what nutrition was appropriate, I wouldn't go to a doctor and I think we should recognise that.

\subsection{Distribution of Supplements}

The quantitative findings emerging from this study reveal that Health food stores are the preferred distribution channel for supplements, with $38 \%$ of the survey population rating this option as their first choice. The second preference is the Pharmacy, with $29.34 \%$ choosing this channel as their preferred option. The least preferred channel is online, where $54 \%$ of the consumers surveyed rated this channel as their least preferred purchase method. Surprisingly, the supermarket option was not rated highly, despite the convenience of this distribution channel. The findings of this survey will help to identify potential marketing routes for Nutritional Supplement manufacturers, as they may currently be focusing much of their budget on online advertising.

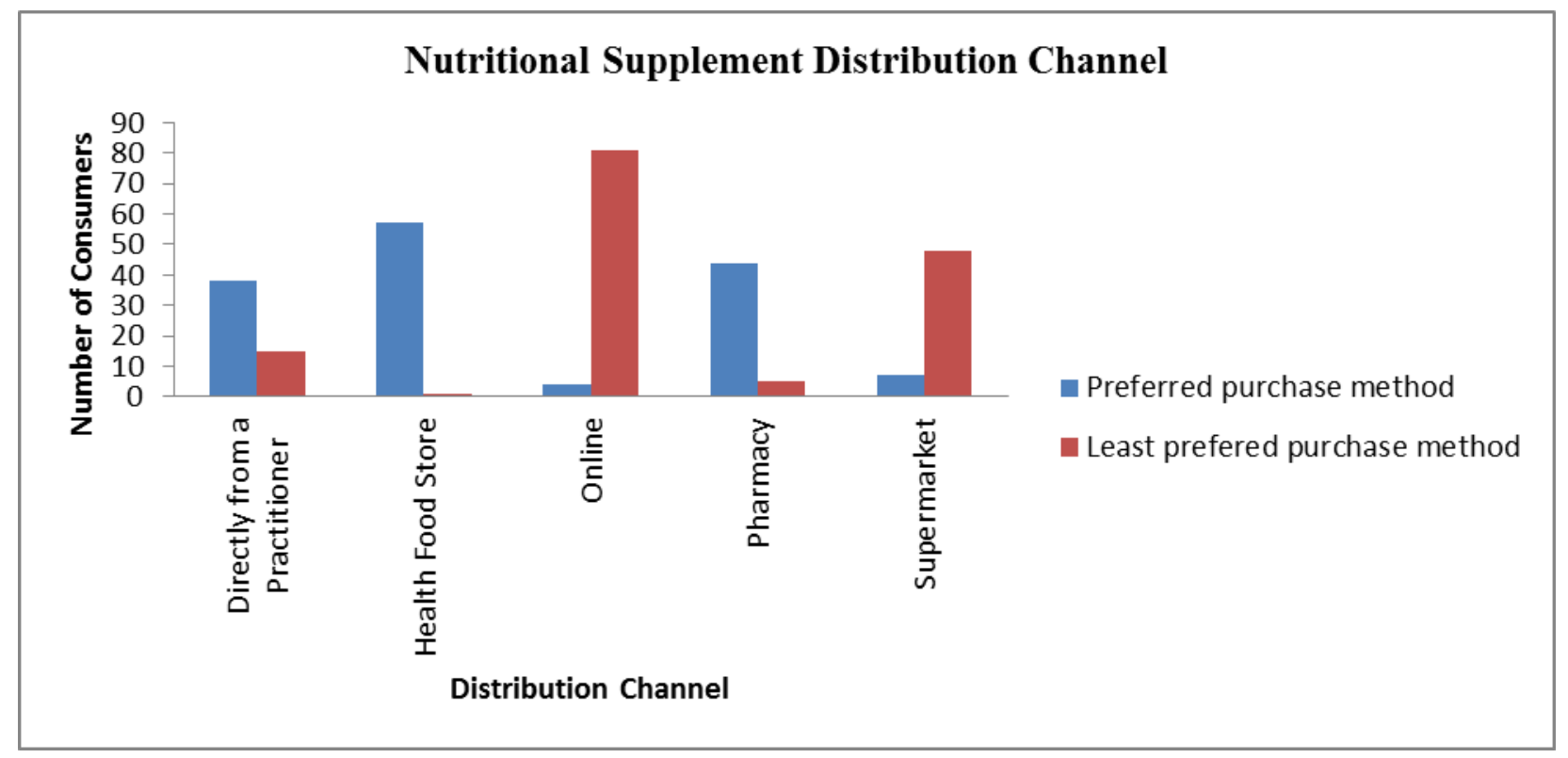

Figure 1. Preferred Distribution Channel for Nutritional Supplements in Ireland

The qualitative findings support the quantitative, and reveal that while movement toward online sales has happened across other industries, clearly this purchase method is not suited as it currently stands to the sale of Nutritional Supplements. One reason could be the lack of personal advice available when purchasing online, as the consumption of Nutritional Supplements requires individual assessment, relative to dietary needs, current medication and the nature of the problem. One interviewee notes that "I disagree with online sales because people don't do enough research - it's like a tertiary form of information. At least in each physical establishment you have the advice. You have that person there in front of you to give you advice if you want it," (Pharmacist). The G.P. interviewed for this current study agrees that "Nutritional Supplements need to be regulated so certainly online, is not a good 


\section{$\triangle 1$ Macrothink}

Business and Economic Research

ISSN 2162-4860

2016, Vol. 6, No. 1

distribution channel". An online Nutritional Supplement retailer outlines her reasons for retailing Nutritional Supplements online. "I think if you look at the statistics, you will see that more of the consumers are moving online, particularly, in the U.K., which has the highest penetration rate of online shopping in Europe. Unfortunately, health supplements at the moment are not probably one of the biggest categories for online sales. I think in a very short period of time online purchasing of supplements will catch up with other industries," (Online Retailer). There are some improvements that can be made to web pages to ensure consumers trust it (online) as a distribution channel. Some online retailers are already doing their utmost to ensure consumers feel informed, safe and secure, when purchasing Nutritional Supplements online. "We post a lot of blogs and those blogs have very themed topics. So, for example in relation to eczema, we would have a blog on natural remedies for eczema, so we post those on a weekly basis. We also have a telephone number, if people want to ring us. What we find is that when people are looking for products online, they prefer to search and read rather than actually engage in a verbal communication. If they want to do that they generally go into a shop and seek it out," (Online Retailer).

\subsection{Nutritional Advice \& Trust}

The chart below presents the findings from the quantitative research outlining the levels of trust attributed to the advisors that are working currently in the Nutritional Supplement Industry. The advisor rated most trustworthy was a Nutritionist; followed by a Dietician and G.P. The least trustworthy source of information was the Media.

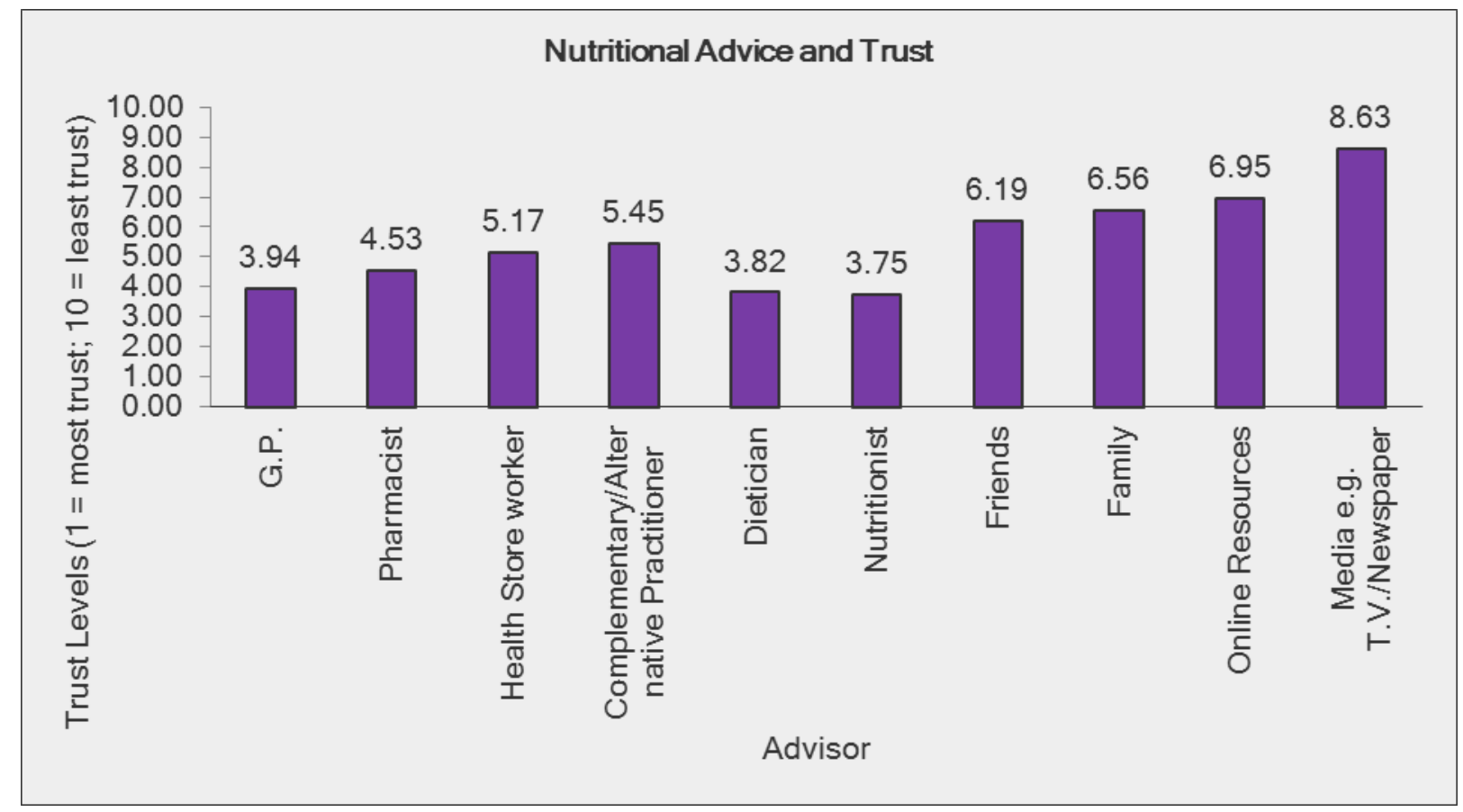

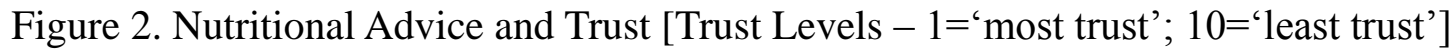

The quantitivie results show that a pharmacist was rated more trustworthy than a Health Food Store worker in terms of giving advice. This is interesting, given that Health Food Stores were rated as the preferred distribution channel as noted in Figure 1. Interestingly, the 


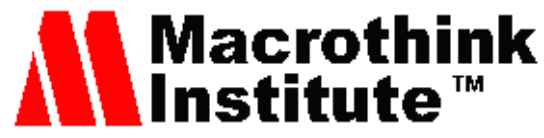

Business and Economic Research

ISSN 2162-4860

2016, Vol. 6, No. 1

findings reveal that when a consumer is faced with a medical query, the number one thing that consumers will do is 'Google it', with $35.3 \%$ admitting to 'almost always' doing this. This is closely followed by 'consulting a G.P.' (34\%) and 'discussing with friends and family' $(32.67 \%)$.

$38 \%$ of survey participants 'almost never' discuss their concerns with a Health Food Store worker, despite this being consumers' preferred distribution channel. This demonstrates an apparent disconnect, as consumers see Health Food Stores as the best place to purchase supplements, yet, the least preferred place to go for advice. Another advisor which appears to have poor trust ratings with the consumer is the Complementary or Alternative Practitioner, whom $37.3 \%$ of those surveyed 'almost never' go to for advice.

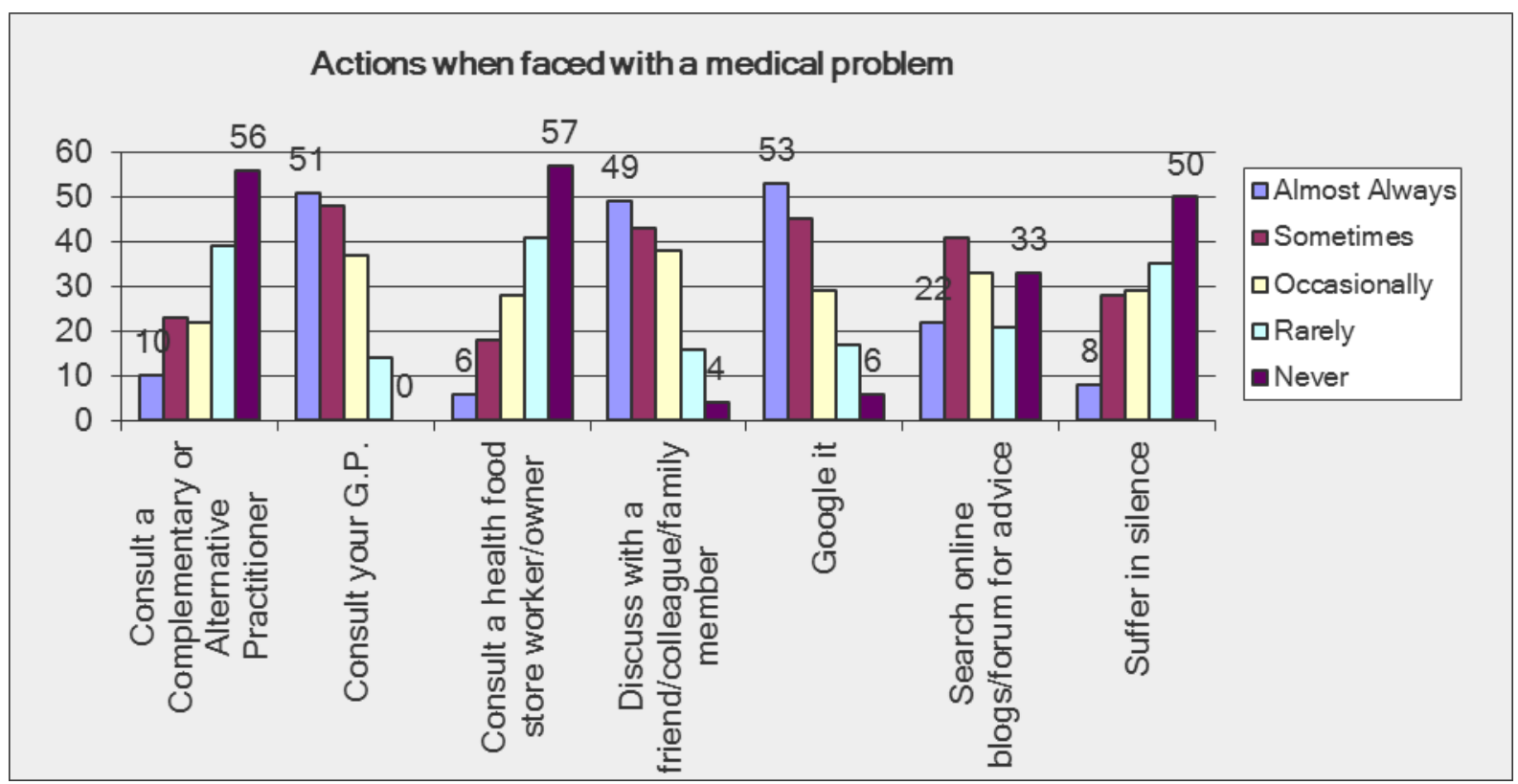

Figure 3. Consumer Actions when Facing a Medical Problem

The qualitative interviews disclose that those working in the industry have a very high self-regard for their own professional expertise. A major finding of this study however is that even though many of the interviewees are working with Supplements, they may not be best positioned to make specific recommendations regarding use of same to consumers. This is based on their lack of study in the first instance, although they may be currently trying to up-skill in relation to the use of Nutritional Supplements.

The consumer survey conducted as part of this investigation ranked in order the following resources as the most trustworthy for information on Nutritional Supplements: Nutritionist; Dietician; G.P. and Pharmacist. Analysis of the level of up-to-date training these experts have had in the last year is interesting: Nutritionists are ranked as number one. The Nutritionist interviewed as part of this current qualitative research stated that "I remember in the early days, you could train in nutritional therapy in under a year, and now, the average length of training is 3 years. So, the profession has seriously matured and someone that has done the 3 years training rather than the 3 hours training (i.e., General Physician training) is much better informed about nutritional supplements and their use". 
A Dietician was ranked as the second most trustworthy source of reliable Nutritional Supplement information. The participants in this study however, had not been recently trained. One Dietician stated-“I haven't had any experience of Nutritional Supplement training in my area of Early Intervention Dietetics,". A second participant made a similar comment. "I haven't undertaken any Nutritional Supplement training in the last year, but it would have been part of our undergraduate education," (Dietician). General Physicians were ranked third by the consumers. The Nutritionist stated that "It shouldn't be an insult, but one of the major medical colleges in Britain gives ten minutes on nutrition in their entire medical training to students". This echoes the findings of Wong et al., (2004) who showed that in 1990, only about one quarter of medical schools required training in medical nutrition sciences, and that of the half of medical schools that offered nutrition electives, many schools achieved only low enrolments (Wong et al., 1004: 754). A General Physician interviewed for this current research commented that "the main source of information in the last year has been reps coming into the practice". The findings of this study corroborate Sobal et al., (1987) who noted that two-thirds of general physicians were interested in continuing medical education about nutrition, with strongest interest among physicians who believed a balanced diet and vitamin supplements were important.

Pharmacists were placed fourth on the trust scale. The pharmacist interviewed as part of this study noted that some training at undergraduate level gave him some information, but unfortunately, he has not received any Nutritional Supplement training since then. "I studied Pharmocognecy in college as part of my qualification. With Pharmacognecy, you are dealing with Alternative or Complementary Medicines and supplementation and plant extracts, so it can give you a feel for combining with medications". The findings of this research study echoed the results of Marques-Vidal (2004), who demonstrated that health science students had less than expected knowledge of Nutritional Supplements.

This study has shown that those who consumers assume to be the best qualified for advice (with the exception of the Nutritionist), are actually not qualified to distribute Nutritional Supplement advice at all. This may have implications for the recommendations and sale of Nutritional Supplements in Ireland. If a person is interested in buying mineral Magnesium for example, and discusses this with their General Practitioner, they may be persuaded not to purchase it as the G.P. has no knowledge as to whether Magnesium would be beneficial for their patient. A similar theory can be suggested for Pharmacies. If a consumer would like a particular form of Magnesium (for example Magnesium Chelate), then the pharmacist may offer the type of Magnesium that they stock in store, with no knowledge or training completed as to the reason a person may require one form over another form.

The sale of Nutritional Supplements is just one service provided by a pharmacy, and in fact for some, their sale appears to be a low priority section. "We would look on Nutritional Supplements as primarily, a link sale, \& be quite cold about it," (Pharmacy Wholesaler). It is difficult to expect a pharmacy to be as qualified in Nutritional Supplements, as someone who studied Nutrition as part of their degree. It would equally be unfair to expect a Nutritionist to understand Pharmacy as well as a Pharmacist. The problem appears to lie with the consumer, who doesn't realise that Dieticians, G.P.'s and Pharmacists are not actually trained in 
Nutritional Supplements, but assume they are qualified in all aspects of nutrition. A national consumer awareness program may be the solution to this misunderstanding.

Health food stores were ranked as the number one place for consumers to purchase Nutritional Supplements. Certain Nutritional Supplement Companies appear to have had an insight into this finding, in that certain brands are deemed primarily for 'Health food store only' sale, for example, Solgar Nature's Plus, Viridian, and Terra Nova. This suggests that some of the producers recognise Health food stores as a superior distribution channel. The level of training that Health food stores received was the highest of all the interviewees. "My staff went to training organized by Wholefoods Wholesale in Cork recently. Three of us are going to Solgar training at the end of this month. We have also had Viridian training in store and Natural Medicine training in store. I have been to Marilyn Glenville's talks in Cork. I have also attended talks at the Rude Health Show, and those would be by Patrick Holford, Marilyn Glenville, Jan de Vries," (Health Food Store Owner \& representative of the Irish Association of Health Food Stores). The second person interviewed as part of this investigation that also has a Health food store commented in a similar fashion. "Training is really important. We attend roughly nine trainings sessions per year". This level of updated training is not known or understood by the consumer, who, while ranking Health food stores as their preferred place to purchase Nutritional Supplements, do not rank Health food store workers highly, when it comes to needing nutritional advice. It can be acknowledged that some Health food store staff attend or participate in training sessions more than others, so, not all Health food stores are equally as qualified or informed as others. A Health Food Store owner outlined that "in their opinion, a health shop is a good place to get information because we have the knowledge - other establishments do not have the training that our staff would have". It would be beneficial, in my opinion, for the Irish Association of Health food stores to market their training and qualifications more clearly to the consumer. A recent campaign in Ireland to encourage consumers to consult with their Pharmacist before going to their G.P. has proven quite successful, with each pharmacy now required to have a private consultation room on site.

\section{Main Recommendations for Practice}

Manufacturers, distributors and retailers need to promote the concept of nutritional training both to themselves, and to consumers. Those who are poorly informed or misinformed need to educate themselves appropriately and efficiently by allocating resources to training or employing more knowledgeable staff. It is recommended that each distribution and advisory channel for Nutritional Supplements attend a certain number of training sessions or programmes per year. As the perception of marketing bias may come from the manufacturers doing the training, it is strongly recommended that the governing body for the Nutritional Supplement Industry - the Food Safety Authority of Ireland, be responsible for the organization and co-ordination of such events.

Consumers need to enquire about training and education of retailers and practitioners, and not assume that all retailers are equal in terms of knowledge. A consumer awareness programme on the safety and benefits of Nutritional Supplements would serve the industry well. This 


\section{Ml Macrothink}

Business and Economic Research

ISSN 2162-4860

2016, Vol. 6, No. 1

should also include recommendations to seek professional accredited advice when choosing Nutritional Supplements. This may fall under the remit of the Government Body 'Safe Food' who is responsible for the promotion of food safety to the consumer, rather than the Food Safety Authority, who's role it is to enforce legislation. A national public awareness campaign could be an effective way of detailing to consumers what they should or shouldn't be taking in terms of supplements. As cautioned by Hunt (2002), care must be taken to ensure any advertised recommendations fit the average requirement for the majority of the public, as that is all that can be expected of national policies realistically. People who fall outside of the averages should be advised to consult with a Nutritionist.

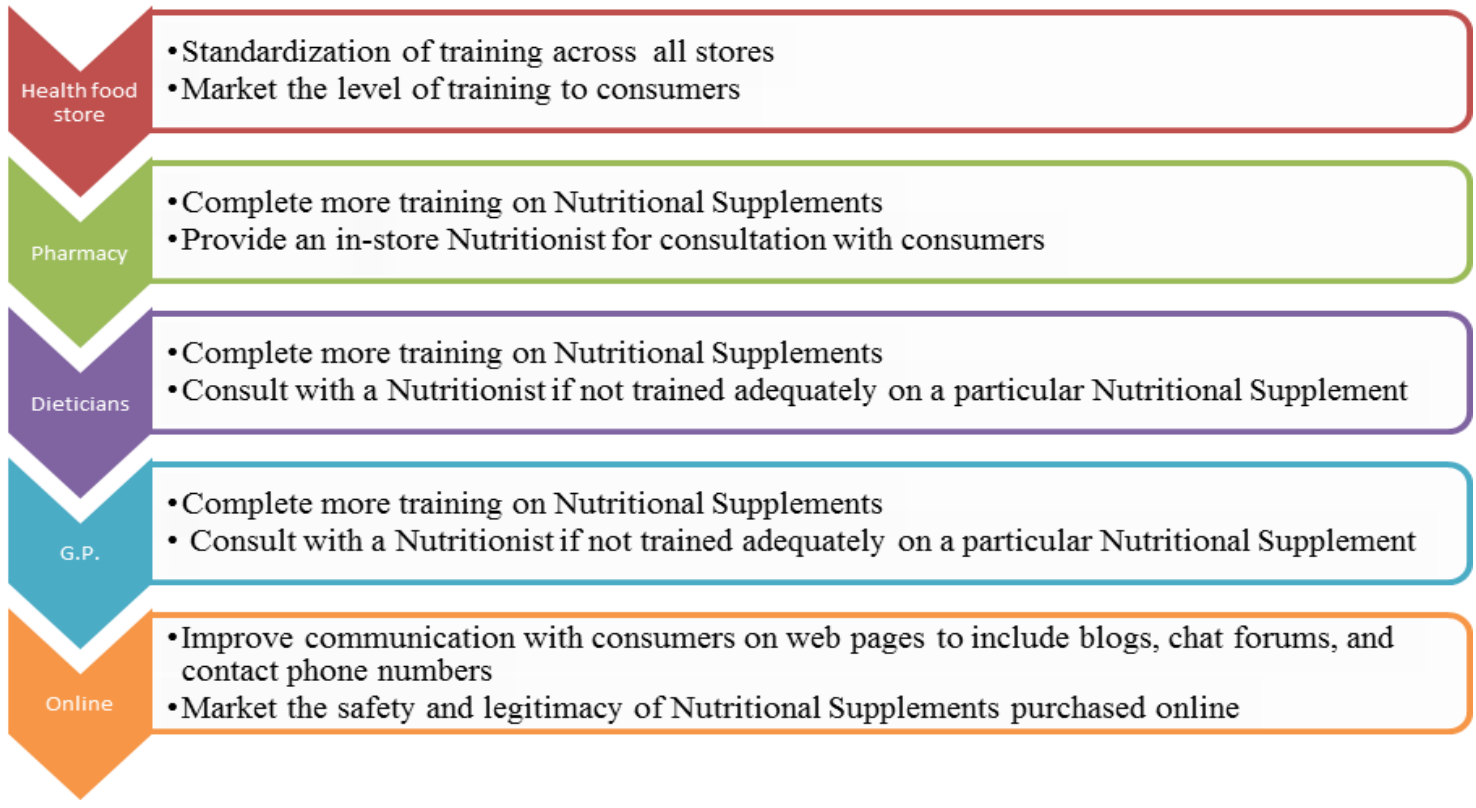

Figure 4. Recommendations for the Distribution of Nutritional Supplements

Government
- Allocate
funding for
consumer
awareness
programs for
Nutritional
Supplements
Assess the need
for increased
resources for
governing
bodies of the
Nutritional
Supplement
Industry

\begin{tabular}{l} 
Governing \\
Bodies \\
- Require all \\
distibution \\
channels for \\
Nutritional \\
Supplements to \\
complete a \\
basic level of \\
training \\
- Provide \\
unbiased \\
training \\
programs for \\
Nutritional \\
Supplement \\
Retailers \\
\hline
\end{tabular}

\begin{tabular}{l} 
Retailers \\
\hline - Complete more \\
Nutritional \\
Supplement \\
qualifications \\
- Promote \\
consumer \\
awareness of \\
the level of \\
training of \\
retail staff \\
\end{tabular}

\begin{tabular}{|l|}
\hline Consumer \\
- Look for \\
advice from \\
qualified health \\
professionals \\
- Shop in stores \\
who actively \\
promote and \\
demonstrate the \\
level of \\
expertise \\
within their \\
staff \\
\end{tabular}

Figure 5. A model for Improving the Nutritional Supplement Industry in Ireland 


\section{Conclusions}

Nutritional Supplements certainly have a role to play in the prevention and treatment of disease. As the Irish population become more aware of their existence and more informed of their uses, practitioners and retailers need to educate themselves in a similar, if not a more thorough manner. Online sources of information need to be vetted, and consumers need to be made aware not to trust everything they read online. More consumer information needs to come from trusted sources, such as the Food Safety Authority to educate people on the benefits of Nutritional Supplementation and the dangers of self-selection of Nutritional Supplements.

The conclusions of this research study confirm that the Nutritional Supplement Industry in Ireland is growing, is vibrant and important. As more retail outlets try to get involved in this sector for commercial gain, it is important that regulation is in place to ensure the credibility of the industry is protected. It has been outlined by interviewees working in the sector that more training is both required and recommended. This study has shown considerable variance in nutritional training and qualification across the current distribution channels. Many of those who consumers see as 'experts' for Nutritional Supplement advice have received little or no training on Nutritional Supplements, and are not actively seeking training voluntarily. A worrying trend is the lack of participation in training events due to time or resource constraints. If a requirement was put on all retailers and advisors of Nutritional Supplements to complete training on an annual basis, consumer confidence would increase.

This research has observed the influence of trust on consumer purchase behaviour. While Health food stores have been determined as the preferred distribution channel for Nutritional Supplements, their workers are not seen as the experts by the public when it comes to nutritional advice when faced with a medical problem. This suggests that consumers are happy to purchase from a Health food store when it comes to health maintenance, but despite the evidence from this study suggesting that health food store workers are the most qualified and current when it comes to training on Nutritional Supplements, consumers are not content to seek their advice when faced with a medical problem. This disconnect needs to be addressed by the Irish Association of Health food stores, especially, as this study has shown them indeed to be one of the most qualified workers in the sector to provide nutritional advice. Not all stores are equally as interested in training or as well trained in Nutritional Supplements. The Health Food Stores, who are qualified and confident in their ability, need to promote the fact that Nutritional Advisers and Nutritionists are available in store for consultation, in a manner similar to the Irish Pharmacy Union, who recently campaigned to draw consumers toward the pharmacy as their first port of call for medical advice (taking the pressure off G.P.s). A national marketing campaign would address these consumer concerns. Furthermore, as consumers assume that professionals in the health care sector are suitable practitioners for recommending Nutritional Supplements, increased allocation of time dedicated to Nutritional Supplements on undergraduate programmes for G.P.s, Dieticians and Pharmacists is duly called for. 


\section{References}

efsa.europa.eu. European Food Safety Authority Definition of a food supplement, Available at: http://www.efsa.europa.eu/en/topics/topic/supplements.htm, Accessed: 19th February 2015 at 8.15 p.m.

Blomqvist K. (1997). The many facets of Trust, Scandinavian Journal of Management, 13(3), 271-286. http://dx.doi.org/10.1016/S0956-5221(97)84644-1

Brasky T. M., Darke A. K., Song X., Tangen C. M., Goodman P. J., Thompson I. M., Meyskens F. L., Goodman G. E., Minasian L. M., Parnes H. L., Klein E. A., \& Kristal A. R. (2013). Plasma Phospholipid Fatty Acids and Prostate Cancer Risk in the SELECT Trial, Journal of the National Cancer Institute, (online journal). Available at: http://jnci.oxfordjournals.org/content/early/2013/07/09/jnci.djt174.abstract. Accessed 1st August 2014, 8.20p.m.

De Jong-van den Berg I. T. W., Hernandex-Diaz S., Werler M. M., Louik C., \& Mitchell A. A. (2004). Trends and predictors of folic acid awareness and periconceptional use in pregnant women, American Journal of Obstetrics and Gynaecology, 192, 121-128. http://dx.doi.org/10.1016/j.ajog.2004.05.085

Dwyer J., Allison D. B., \& Coates P. M. (2005). Dietary Supplements in Weight Reduction, Supplement to the Journal of the American Dietetic Association, 105, s80-s86. http://dx.doi.org/10.1016/j.jada.2005.02.028

Fox S., \& Fallows D. (2003). Internet health resources: Health searches and e-mail have become more commonplace, but there is room for improvement in searches and overall Internet access, Pew Internet Research, PEW Internet and American Life Project. Available at: http://www.pewinternet.org. Accessed 22nd March 2013 at 8.15 p.m.

Frenkel M., Ben Ayre E., Carlson C., \& Sierpina V. (2008). Integrating complementary and alternative medicine into conventional primary care: The Patient Perspective, Explore, 4, 178-186. http://dx.doi.org/10.1016/j.explore.2008.02.001

Gino F. (2008). Do we listen to advice just because we paid for it? The impact of advice cost on its use, Organizational Behaviour and Human Decision Processes, 107, 234-245. http://dx.doi.org/10.1016/j.obhdp.2008.03.001

Greger J. (2001). Dietary supplement use: Consumer characteristics and interests, Journal of Nutrition, 131(4), 1339s-1349. PMid:11285350

Hamzaoui-Essoussi L., Sirieix L., \& Zahaf M. (2013). Trust orientations in the organic food distribution channels: A comparative study of the Canadian and French markets, Journal of $\begin{array}{llll}\text { Retailing } \quad \text { and } & \text { Consumer } & \text { 292-301. }\end{array}$ http://dx.doi.org/10.1016/j.jretconser.2013.02.002

Hunt J. R. (2002). Tailoring advice on dietary supplements: An opportunity for dietetics professionals, Journal of the American Dietetic Association, 102(12), 1744-1745. http://dx.doi.org/10.1016/S0002-8223(02)90377-9 
Jodlbauer B., \& Jonas E. (2011). Forecasting clients' reactions: How does the perception of strategic behaviour influence the acceptance of advice, International Journal of Forecasting, 27, 121-133. http://dx.doi.org/10.1016/j.ijforecast.2010.05.008

Kennedy J. (2005). Herb and Supplement Use in the US Adult Population, Clinical Therapeutics, 27(11), 1847-1858. http://dx.doi.org/10.1016/j.clinthera.2005.11.004

Marques-Vidal P. (2004). Vitamin supplement usage and nutritional knowledge in a sample of Portuguese health science students, Nutrition Research, 24, 165-172. http://dx.doi.org/10.1016/j.nutres.2003.10.001

Mechanic D., \& Schlesinger M. (1996). The impact of managed care on patients' trust in medical care and their Physicians, JAMA, 275(21), 1693-1697. http://dx.doi.org/10.1001/jama.1996.03530450083048

Oxford Dictionary. (2013). Definition of Power, Available at: http://oxforddictionaries.com/definition/english/power, accessed January 5th, 2016.

Petroczi A., Taylor G., \& Naughton D. P. (2010). Mission impossible? Regulatory and enforcement issues to ensure safety of dietary supplements, Food and Chemical Toxicology, 49, 393-402. http://dx.doi.org/10.1016/j.fct.2010.11.014

PewResearch Centre. (2000). The online health care revolution: how the web helps Americans take better care of themselves, PEW Internet and American Life Project. Available at: http://www.pewinternet.org. Accessed 22nd March 2015 at 7.40 p.m.

Rozmovits L., \& Ziebland S. (2004). What do patients with prostrate or breast cancer want from an Internet site? A qualitative study of information needs, Patient Education and Counselling, 53, 57-64. http://dx.doi.org/10.1016/S0738-3991(03)00116-2

Saunders M., \& Lewis P. (2007). Research Methods for Business Students, Harlow: Pearson Education.

See K. E., Morrison E. W., Rothman N. B., \& Soll J. B. (2011). The detrimental effects of power on confidence, advice taking, and accuracy, Organizational Behaviour and Human Decision Processes, 116, 272-285. http://dx.doi.org/10.1016/j.obhdp.2011.07.006

Sillence E., Briggs P., Harris P., \& Fishwick L. (2006). A framework for understanding trust factors in web-based health advice, International Journal of Human-Computer Studies, 64, 697-713. http://dx.doi.org/10.1016/j.ijhcs.2006.02.007

Smart J. M., \& Burling D. (2001). Radiology and the Internet: a systematic review of patient information resources, Clinical Radiology, 56(11), 867-870. http://dx.doi.org/10.1053/crad.2001.0738

Sobal J., Muncie H. L., Valente C. M., DeForge B. R., \& Levine D. (1987). Physicians' beliefs about vitamin supplements and a balanced diet, Journal of Nutrition Education, 4, 181-185. http://dx.doi.org/10.1016/S0022-3182(87)80187-5

Song J., \& Zahedi F. (2007). Trust in health infomediaries, Decision Support Systems, 43, 
390-407. http://dx.doi.org/10.1016/j.dss.2006.11.011

Verbeke W., \& de Bourdeauhuij L. (2007). Dietary behaviours of pregnant women versus non-pregnant women, Appetite, 48, 78-86. http://dx.doi.org/10.1016/j.appet.2006.07.078

Wong V., Millen B. E., Geller A. C., Rogers A. E., Maury J. J., \& Prout M. N. (2004). What's in store for medical students? Awareness and utilization of expert nutrition guidelines among medical school preceptors, Preventative Medicine, 39, 753-759. http://dx.doi.org/10.1016/j.ypmed.2004.02.046

\section{Copyright Disclaimer}

Copyright for this article is retained by the author(s), with first publication rights granted to the journal.

This is an open-access article distributed under the terms and conditions of the Creative Commons Attribution license (http://creativecommons.org/licenses/by/3.0/). 